\title{
Making friends with your team: The benefits of raising learner awareness of intra-team relations
}

\author{
Robinson, Bryan J. ${ }^{a}$ and Olvera-Lobo, M. Dolores ${ }^{\text {b }}$
}

${ }^{\mathrm{a}}$ Department of Translation and Interperting, University of Granada, Spain, ${ }^{\mathrm{b}}$ Department of Information and Communication, University of Granada, Spain.

\begin{abstract}
To highlight the importance of teamwork and intra-team relationships beyond the classroom, in a small study population of undergraduate students of Translation studies, we have attempted to raise awareness of teamwork processes so as to empower learners in managing their interaction and ensure they gain valuable pre-professional experience. Following specific input and the construction of randomized teams, we questioned learners about their previous and current experience of teamwork, their knowledge of team colleagues and the changes their relationships underwent, and prior academic performance versus expectations of current performance and how teamwork might influence this. Our results indicate teamwork substantially improved levels of intimacy, enhanced the quality of the experience, and raised awareness of the benefits of the team per se. However, some learners recognized personal difficulties with teamwork that they were unable to overcome and, in this context, "people problems" became increasingly important. Nonetheless, learners were convinced that teamwork would have a positive influence on their final grades.
\end{abstract}

Keywords: Tertiary education; Teamwork competencies; Intra-team relations; Translator training. 


\section{Introduction}

Post-Bologna tertiary education embraces a broad-ranging concept of learner training with a specific focus on graduate employment prospects. Hence, generic competencies relating to the workplace form an integral part of undergraduate programs. However, in Translation Studies-and elsewhere?-learners generally remain unaware of the importance of teamwork and intra-team relationships and believe that teamwork has little relevance beyond the classroom. Foregrounding teamwork-related competencies (Robinson et al. 2016) to raise awareness of the processes involved should empower learners in managing their interaction and ensure they gain valuable pre-professional experience. Here, we look at three areas of team interaction and their relations with facets of learner experience: (1) learners' conclusions about their teamwork experience versus their experience during the current module; (2) learner knowledge of colleagues and the changes their relationships undergo; and (3) prior academic performance, expectations of current performance, and learner perceptions of the influence teamwork might have on performance.

\subsection{Awareness-raising input}

To raise awareness of team processes and encourage learners to be proactive in dealing with issues arising from interpersonal interaction, task fulfilment, leadership, decisionmaking and conflict resolution we have drawn on business management and training (Birkenbihl 1977; Tuckman 1965), and elicited the experience of earlier cohorts to provide input on the theory and practice of small group learning (Robinson 2017). We discuss group formation and intra-group processes that receive little attention in tertiary education (Robinson et al. 2015). We describe Tuckman's four-stage model so learners can appreciate that Forming, Storming, Norming and Performing are normal, natural processes they need to understand, accept and manage to benefit themselves and their colleagues. Earlier cohorts had expressed apprehension about teamwork (Robinson 2017) so our objectives for this input have been:

- To identify and define Tuckman's four stages in the life of a team

- To identify crucial points in the group formation process, and

- To encourage a proactive response to "crises" so learners can see how

- To manage these "crises" and advance in team and task development

- To distinguish between cooperative and collaborative learning

- To promote genuine, interaction through cooperative learning

- To highlight the difficulties and underline the advantages of iterative interpersonal interaction in cooperative learning

- To allay learners' quite reasonable fears

- To encourage learners to see the negative aspects of teamwork as obstacles that can be overcome 
- To reassure learners by quoting learners from earlier cohorts who had concluded that the positive aspects of teamwork outweigh the obstacles.

\subsection{Objectives}

The present study seeks to determine the nature and level of impact on learner awareness of intra-team interaction processes. Specifically, we hope to establish whether or not learners are more aware of (1) the added value of the team per se in improving task performance; (2) the individual's responsibility to contribute to team performance; and (3) the potential personal and academic benefits of making a commitment to the team.

\section{Method}

This is a quantitative study of data collected via a Google Forms online survey and represents part of ongoing research based on learner-generated materials published elsewhere (Robinson et al 2015, 2016 Robinson 2014, 2015, 2017). The learner population $(\mathrm{n}=31$, respondents $=22(71 \%)$ ) came from a Specialized Translation module taught at the University of Granada (Spain). The module is delivered using a cooperative, project-based, methodology (Olvera-Lobo et al. 2007) involving randomly assigned teams (Robinson et al. 2015). Course assessment is continuous (60\%) - three team translation tasks plus an individual midterm examination — and summative (40\%) — an individual final examination. Final assessment favors the individual (55\%) over the team (45\%).

\subsection{Participants}

Demographic data show the group was typical of our context: 82\% (18) women; age 20-23 (mode 21 years (15)); 86\% (19) native speakers of Spanish, 13.5\% (3) speakers of other European languages; $81.8 \%$ (18) from the University of Granada, $18.2 \%$ national or European exchange students; $95.5 \%$ (21) following programs in Translation Studies.

\subsection{Instrument}

Participants accepted a declaration of informed consent before providing demographic data. Then identified their team and labeled colleagues as "Person A", "Person B", and so on.

\section{Results}

\subsection{Previous experience of teamwork vs. current experience}

We asked learners to describe their previous experience of teamwork on a five-point scale ranging from $1=$ Terrible to $5=$ Excellent. They then recorded the best and the worst parts of that experience before responding to similar items about the current module

Prior experience of teamwork was positive with $94.5 \%$ (21) choosing options three or four (Fig. 1). Responses referring to the current module ranged across the scale but the clear 
trend was towards "Excellent". Some $40.9 \%$ chose "Excellent" and another $40.9 \%$ chose option three or option four. However, four learners chose option one ("Terrible") or option two. To seek explanations for these responses we analyzed the short answer items, categorised topics, and quantified responses (Tables 1 and 2).

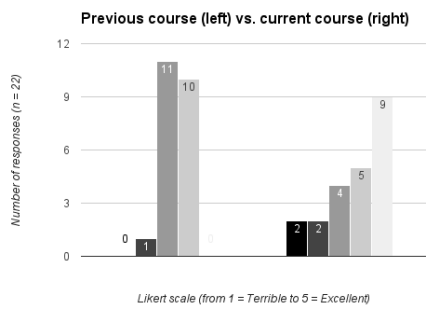

Figure 1. Prior experience of teamwork vs. current experience

One learner reported that nothing had been good about his or her prior experience and three stated nothing had been bad. Six respondents considered that the best part of teamwork was learning from others and four signalled the benefits of positive interaction to produce the translation product. Learners were positive about the motivating stimulus they received when working with others and the benefits of feeling supported; the advantages of organizing and sharing work; and the resulting speed with which they completed their work.

Table 1. Best vs. worst of prior experience of teamwork

\begin{tabular}{lclc}
\hline Best parts & $\mathbf{N}^{\mathbf{0}}$ responses & Worst parts & $\mathbf{N}^{\mathbf{0}}$ responses \\
\hline None & 1 & None & 3 \\
Learning from others & 6 & Collective decision-making & 1 \\
Dividing/sharing the work & 3 & Logistics of meetings & 5 \\
Productive interaction & 4 & Modus operandi of individuals & 2 \\
Motivation and support & 3 & Antipathy towards others/teamwork & 3 \\
Speed & 3 & Time & 1 \\
& & Communication & 1 \\
& & Lack of commitment/responsibility & 6 \\
\hline
\end{tabular}

Negative experiences centered on the lack of responsibility and/or commitment of others; the inevitable frustration at finding it difficult to arrange meetings; problems arising from the work styles of specific individuals; and individaul's personal difficulties when working in teams. 
Table2. Best vs. worst of current experience of teamwork

\begin{tabular}{|c|c|c|c|}
\hline Best parts & $\mathbf{N}^{0}$ responses & Worst parts & $\mathrm{N}^{0}$ responses \\
\hline None & 2 & None & 9 \\
\hline Learning from others & 4 & & \\
\hline Dividing/sharing the work & 2 & & \\
\hline \multirow[t]{3}{*}{ Productive interaction } & 6 & Modus operandi & 4 \\
\hline & & $\begin{array}{l}\text { Antipathy towards } \\
\text { others/self }\end{array}$ & 3 \\
\hline & & Time & 4 \\
\hline $\begin{array}{l}\text { Motivation/commitment/personal } \\
\text { growth/responsibility of } \\
\text { colleagues }\end{array}$ & 7 & $\begin{array}{l}\text { Lack of } \\
\text { commitment/responsibility }\end{array}$ & 3 \\
\hline & & Conflict & 1 \\
\hline
\end{tabular}

Two learners found nothing good about the current module and nine found nothing bad about it (Table 2). All the "best parts" are related to the processes involved in fulfilling team tasks and personal attitudes shown by colleagues. Seven negative comments focussed on "people problems": relating to colleagues and individual difficulties in interacting successfully; lack of commitment or responsibility; conflict; antipathy towards others; and a personal difficulties when working in a team.

\subsection{Interpersonal relations within teams}

We asked our respondents how well they had known each other at the start and how well they knew each other at the end of the course. Responses were on a five-point scale: Not at all. Acquaintance. Casual friend. Close friend. Intimate friend. Table 3 illustrates changes in the level of intimacy of relationships over 12 weeks.

\subsection{Effects of randomization}

Randomization created teams in which $66 \%$ of relationships were between individuals who stated they knew each other "Not at all"; 28\% were categorised as "Acquaintance" or "Casual friend". Only 2.3\% described another person as an "Intimate friend". Hence, we had genuinely created teams of individuals who were new to each other. Consequently, we could expect changes in the degree of intimacy of their relations to appear over the semester. We classified changes in the level of intimacy from "Minus 2" through to "Plus 3" (Table 4, Fig. 2). 
Some $29.5 \%$ of relations showed "Zero change". These mainly represented learners who began and ended the course without getting to know one of their colleagues $(9.1 \%)$; a further $10.2 \%$ remained at the Acquaintance to Acquaintance level.

Table 1 Course initial vs. course final levels of intimacy

\begin{tabular}{lllll}
\hline & \multicolumn{2}{l}{$\begin{array}{l}\text { Initial relations } \\
\mathbf{n = 2 2} ; \mathbf{n}^{\mathbf{0}} \text { colleagues } \mathbf{4}\end{array}$} & \multicolumn{2}{l}{$\begin{array}{l}\text { Course-final relations } \\
\mathbf{n = 2 2} ; \mathbf{n}^{\mathbf{0}} \text { colleagues = 4 }\end{array}$} \\
\hline Not at all & $65.91 \%$ & $(58)$ & $11.36 \%$ & $(10)$ \\
Acquaintance & $19.32 \%$ & $(17)$ & $43.18 \%($ & $38)$ \\
Casual friend & $9.09 \%$ & $(8)$ & $31.82 \%$ & $(28)$ \\
Close friend & $3.41 \%$ & $(3)$ & $7.95 \%$ & $(7)$ \\
Intimate friend & $2.27 \%$ & $(2)$ & $3.41 \%$ & $(3)$ \\
No comment & $0.00 \%$ & $(0)$ & $2.27 \%$ & $(2)$ \\
Total responses & $100.00 \%$ & $(88)$ & $100.00 \%$ & $(88)$ \\
\hline
\end{tabular}

In contrast $63 \%$ of relationships increased in level of intimacy by one, two or even three degrees. Some $34.1 \%$ of relationships changed from "Not at all" to "Acquaintance"; $17 \%$ from "Not at all" to "Casual friend"; and a further 3.4\% changed by three levels from "Not at all" to "Close friend".

Table 2. Changes in levels of intimacy

\begin{tabular}{lrll}
\hline Degree of change & Initial relations & Course-end relations & Percentage instances (n) \\
Minus 2 & Casual friend & Not at all & $1.1 \%(1)$ \\
Minus 1 & Acquaintance & Not at all & $1.1 \%(1)$ \\
Minus 1 & Not at all & No comment & $1.1 \%(1)$ \\
Zero change & No comment & No comment & $1.1 \%(1)$ \\
Zero change & Not at all & Not at all & $9.1 \%(8)$ \\
Zero change & Acquaintance & Acquaintance & $10.2 \%(9)$ \\
Zero change & Casual friend & Casual friend & $4.5 \%(4)$ \\
Zero change & Close friend & Close friend & $2.3 \%(2)$ \\
Zero change & Intimate friend & Intimate friend & $2.3 \%(2)$ \\
Plus 1 & Not at all & Acquaintance & $34.1 \%(30)$ \\
Plus 1 & Acquaintance & Casual friend & $9.1 \%(8)$ \\
Plus 1 & Casual friend & Close friend & $2.3 \%(2)$ \\
Plus 1 & Close friend & Intimate friend & $1.1 \%(1)$ \\
Plus 2 & Not at all & Casual friend & $17.0 \%(15)$ \\
Plus 3 & Not at all & Close friend & $3.4 \%(3)$ \\
& & & $100.0 \%(88)$ \\
\hline
\end{tabular}


These changes were contrasted in four instances: one respondent initially selected "No comment" with respect to one relationship and maintained this at the end of the course; another first selected "Not at all" and finally selected "No comment"; a third described a loss of intimacy of one level - from "Acquaintance" to "Not at all"; and a fourth respondent described a loss of two levels - from "Casual friend" to "Not at all". These responses may indicate prior conflict or superficial relationships that deteriorated over the semester.

\subsection{Influence on grades}

We asked learners to report their grade for a similar module and their expectations for the current module. Figure 3 shows that $40.9 \%$ had achieved a Credit but $4.5 \%$ had failed the previous module. However, expectations were high with $77.3 \%$ expecting a Credit and $0 \%$ expecting a Fail. Interestingly, $13.6 \%$ reported a Distinction on the previous course and the same percentage expected to earn that same grade on the present module.

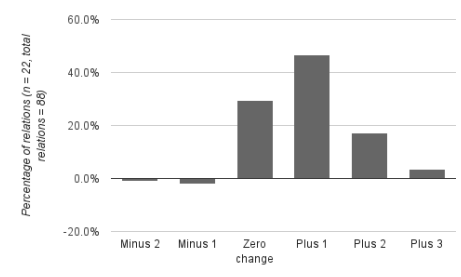

Figure 2. Degree of difference in relations

Some $63.6 \%$ stated that the teamwork option would influence their final grade and $77.3 \%$ believed this influence would be positive.

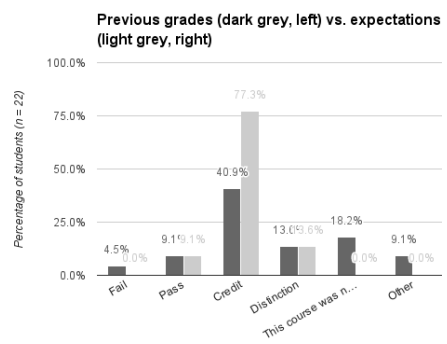

Figure 3. Previous grades (blues) vs. Expected grades (red) 


\section{Conclusions}

In the present limited, small-scale study, we have found that:

- In randomized teams with $66 \%$ of new relationships, teamwork substantially improved levels of intimacy beyond mere "working relationships"

- Though prior experience of teamwork was good, on the module under study the quality of that experience was enhanced

- While some participants were already aware of the benefits of learning from each other, mutual motivation and support, an increasing number expressed their appreciation of these factors

- A few learners recognized personal difficulties with teamwork that they were unable to overcome

- Lack of commitment and lack of responsibility were "people problems" that became increasingly important on the module under study

- Learners were convinced that teamwork would have a positive influence on their final grades.

\section{References}

Birkenbihl, M. (1977a). Train the trainer in effective course design and presentation. Bromley, Kent: Chartwell-Bratt (Publishing and Training) Limited.

Olvera-Lobo, M. D., Robinson, B. J., Castro Prieto, R. M., Quero Gervilla, E., Muñoz Martín, R., Muñoz Raya, E., Díaz Lerma, J. L. (2007). A professional approach to translator training (PATT). Meta : Journal Des Traducteurs / Meta: Translators' Journal, 53(3), 517-528.

Robinson, B. J. (2014). Como mejorar el aprendizaje mediante el uso de herramientas de la Web 2.0. In C. Vargas Sierra (Ed.), TIC, trabajo colaborativo e interacción en Terminología y Traducción (pp. 243-258). Granada: Editorial Comares.

Robinson, B. J. (2016). Small group learning. theory and practice. Available at http://hdl.handle.net/10481/44531.

Robinson, B. J. (2017). Learner concerns about generic competencies: If I use teamwork, should I not provide input on basic interactive skills? In S. Hagemann, J. Neu \& S. Walter (Eds.), Translationslehre und bologna-prozess: Unterwegs zwischen einheit und vielfalt / translation/interpreting teaching and the bologna process: Pathways between unity and diversity. Berlin: Frank \& Timme.

Robinson, B. J., Olvera-Lobo, M. D., \& Gutiérrez-Artacho, J. (2016). After Bologna: Learner- and competence-centred translator training for 'Digital natives'. In C. Martín de León, \& V. González-Ruiz (Eds.), From the lab to the classroom and back again: Perspectives on translation and interpreting training. (pp. 325-359). Frankfurt am Main: Peter Lang.

Robinson, B. J., Olvera-Lobo, M. D., \& Gutiérrez-Artacho, J. (2015). Trainee translators' perceptions of collaborative teamwork. In G. Corpas Pastor, M. Seghiri Domínguez, R. 
Gutiérrez Florido \& M. Urbano Mendaña (Eds.), Nuevos horizontes en los estudios de traducción e interpretación (comunicaciones completas) / new horizons in translation and interpreting studies (full papers) / novos horizontes dos estudos da tradução e interpretação (comunicações completas) (pp. 480-498). Geneva: Tradulex.

Tuckman, B. W. (1965). Developmental sequence in small groups. Psychological Bulletin, 63(6), 384-399. doi:10.1037/h0022100 